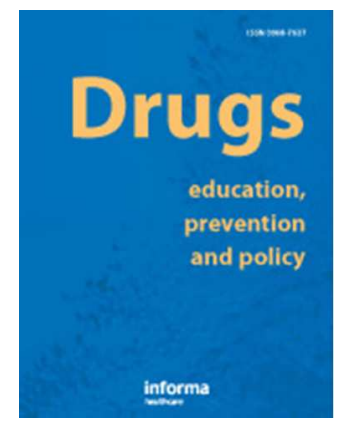

\title{
Moderate drinking before the unit: Medicine and life assurance in Britain and the US c.1860-1930
}

\begin{tabular}{|r|l|}
\hline Journal: & Drugs: Education, Prevention \& Policy \\
\hline Manuscript ID: & Draft \\
\hline Manuscript Type: & Original papers \\
\hline Keywords: & Alcohol, Risk, Harm reduction \\
\hline & \\
\hline
\end{tabular}

SCHOLARONE ${ }^{m}$

Manuscripts 
Moderate drinking before the unit: Medicine and life assurance in Britain and the US c.1860-1930

\begin{abstract}
This paper describes the way in which 'Anstie's Limit' - a particular definition of moderate drinking first defined in Britain in the 1860s by the physician Francis Edmund Anstie (1833-1874) - became established as a useful measure of moderate alcohol consumption. Becoming fairly well-established in mainstream Anglophone medicine by 1900, it was also communicated to the public in Britain, North America and New Zealand through newspaper reports. However the Limit also travelled to less familiar places, including life assurance offices, where a number of different strategies for separating moderate from excessive drinkers emerged from the dialogue between medicine and life assurance. While these ideas of moderation seem to have disappeared into the background for much of the twentieth century, re-emerging as the 'J-shaped' curve, these early developments anticipate many of the questions surrounding uses of the 'unit' to quantify moderate alcohol consumption in Britain today. The paper will therefore conclude by exploring some of the lessons of this story for contemporary discussions of moderation, suggesting that we should pay more attention to whether these metrics work, where they work, and why.
\end{abstract}

Keywords:

Alcohol - risk - harm reduction 
Moderate drinking before the unit: Medicine and life assurance in Britain and the US c.1860-1930

Introduction

This paper describes the way in which 'Anstie's Limit' - a particular definition of moderate drinking first defined in Britain in the 1860s by the physician Francis Edmund Anstie (1833-1874) - became established as a useful measure of moderate alcohol consumption. The idea of moderation has a longer history than can be adequately covered here, but its definition seems to have become bound up with quantifiable limits after Anstie established a safe daily limit for personal consumption. This quantification of moderate drinking travelled from its origins in experimental medicine into everyday medical practice via a number of sites, including the offices of life assurance firms, and had a particular geography, beginning as a largely British response to European research on alcohol, and then spreading through the US and the rest of the Anglophone world. This history of this development has received relatively little attention, with one recent book arguing that "Victorians did not distinguish between moderate drinking and drunkenness" (Duncan, 2013: 17; though see Woiak, 1994). Historians of drinking have tended to concentrate on the rise of the disease theory of alcoholism, but the medicalization of drinking has always been a 'hybrid project' combining physiological, psychiatric and epidemiological elements, with all three present in discussions of alcohol from the middle of the nineteenth century (Valverde, 1998). Physiological investigations into the action of alcohol on the human body did not disappear during this period and were in fact influential in establishing both an idea of moderation and a way of measuring it. Its significance for life assurance might seem surprising but nineteenth-century life assurance turns out to have been a highly productive site of knowledge production (Alborn, 2001, 2009; Berridge, 1977; Dupree, 1997; 
Jureidini and White, 2000; Porter, 1995). Life assurance firms collected information that appeared to show the effects of different diseases and habits on mortality and insisted that applicants underwent medical examination to screen against risks, including drink (Kneale and French, 2013). In doing so they helped to develop medical knowledge and practice amongst elite physicians and general practitioners.

We would also like to suggest that a discussion of the Limit can help us think about the contemporary limits associated with the 'unit' in Britain and the 'standard drink' in the US and elsewhere in new and productive ways. These metrics all refer to particular volumes of pure alcohol the unit is $10 \mathrm{ml}$ - which makes it possible to compare different alcoholic drinks. In Britain recommended limits for weekly and daily consumption were established in the 1990s, measured by a particular number of units, much as Anstie's Limit was measured in ounces of pure alcohol. The contemporary unit has attracted a good deal of attention from historians and social scientists who have noted that the UK's recommended limits were reportedly 'plucked out of the air' in an arbitrary fashion (Thom, 1999, p. 129; Greenaway, 2003). Both limits and units have subsequently been treated as an attempt to use spurious public health arguments to hide neoliberal and/or temperance attempts to survey and discipline drinkers through making them aware of their own consumption (e.g. Jayne et al., 2012). Drawing on work from Science and Technology Studies we might suggest that what is significant is not where units and limits came from but whether they work, in which contexts, and why. The drinkers in Jayne et al.'s survey did not use units to track their drinking, and the UK public is often uncertain about the specified daily limits, which suggests that these are not effective in encouraging drinkers to monitor their health. On the other hand, public health researchers have found units and limits more useful as ways of identifying risks, as have underwriters working in life assurance. As a measure of alcoholic potency units also played a part in plans for 


\begin{abstract}
Minimum Unit Pricing (see XXX in this issue). We are reminded of Bruno Latour's recommendation that "In order to make a diagnosis or a decision about the absurdity, the danger, the amorality, or the unrealism of an innovation, one must first describe the network" - in other words the particular chains of actors in which units or limits find themselves $(1991,130)$. So it is not that we should reject the unit, as Jayne et al. urge us to do - we might as well reject the kilometre - as the contexts in which it is demonstrably acting upon us in unwelcome ways.
\end{abstract}

If we consider the unit from the point of view of metrology and translation - which requires thinking about how ideas, practices, and materials move from one setting to another, and what has to be done for this movement to happen successfully (Latour, 1987) - then we can see that the contemporary unit and Anstie's Limit manage this movement with relative facility. In fact they were constructed as metrics because that is one of the things metrics do best - they allow things to be translated into something else: "all measures... construct a commensurability that did not exist before their own calibration" (Latour, 1993: 113). However we will see that Anstie's limit worked in some of these new contexts and not others, and these outcomes could sometimes be rather unexpected. Where and how did the Limit become authoritative, in other words, and why? It is worth remembering that "Domination is an effect not a cause" (Latour, 1991: 130) when we consider the fate of the contemporary unit and its associated limits.

\footnotetext{
The paper begins by introducing Anstie and the work that established his Limit, as well as tracing its progress towards general acceptance by mainstream medicine in Britain. It then considers the role of life assurance in shaping uses of the Limit in doctors' examination rooms and within the industry. The history of the Limit ends with Prohibition and the appearance of Raymond Pearl's claim (in
} 
Alcohol and Longevity, 1926) that moderate drinkers enjoyed better longevity than abstainers. The paper concludes by returning to consider the unit in the light of this discussion.

Anstie's Limit

While Anstie held leading positions at several of the London hospitals, Anstie was most closely associated with the Westminster, where he lectured in forensic medicine and materia medica before becoming Physician in 1873 (Anon., 1874a, 1874b; Earles, 2004). Anstie's research focused on diseases of the nervous system as well as the effects of alcohol and other drugs; he edited the journal The Practitioner from 1868 and was a member of the editorial staff of the Lancet. As an agitator for public health he played a key role in the Lancet's 1865 investigation of workhouse infirmaries and the establishment of an association for Poor-law Medical Officers. A close supporter of the Provisional Committee for the London School of Medicine for Women, he would have been the School's first Dean had it not been for his early death in 1874 (Bell, 1953).

Between 1860 and 1874 Anstie challenged established ideas about alcohol while insisting that a scientific case for moderate consumption should be made despite the fierce opposition of teetotallers pressing for total abstinence. In the 1830s Justus von Liebig had argued that alcohol was a food, an opinion with which Anstie's mentor Dr Robert Bentley Todd had agreed, but in 1860 the French researchers Lallemand, Duroy and Perrin suggested that alcohol could not be a food as it passed through the body unchanged (Krasnick, 1985). To teetotallers familiar with Joseph's Livesey's 'Malt Lecture' this seemed to confirm that alcohol was an unnecessary, unnatural and harmful presence in the body (McAllister, 2014). From his very earliest publications on alcohol Anstie was convinced that 
alcohol was not simply a poison, food or medicine in and of itself, and that its effects depended upon the dose administered: "Below a certain dose this substance is a pure stimulant, so far as regards its action on the nervous system. Above this dose its effect is a wholly depressing one" (1862: 713). Expanding on this, he suggested "So long as there is any need for alcohol in the system it will fail to intoxicate; the moment that the faintest symptom of intoxication appears, we may be sure that the further use of this agent would be injurious" (715). Anstie undertook sophisticated experimental work to measure the quantities of alcohol that were eliminated in urine, breath and sweat, becoming certain that "a moderate or non-intoxicating" dose of alcohol produced only tiny quantities of eliminated alcohol, while large doses meant that "large quantities of unchanged alcohol rapidly appear in the breath, the sweat, and more especially in the urine" (1865: 344). He concluded that the body appeared to benefit from alcohol, up to a certain dose. Beyond this it ceased to be a food or stimulant, with two further results: firstly it began to act as a sedative, with obvious narcotic and harmful effects (the drinker became drunk and the body began to suffer the consequences of drinking); and secondly excess alcohol began to be eliminated from the body.

By 1870 these experiments had established what would become known as 'Anstie's Limit': a “daily allowance" of 1 or $1 \frac{1 / 2}{2}$ ounces of absolute alcohol that was "about the limit of what can be habitually taken by persons leading a not very active life, without provoking symptoms of chronic malaise indicative of actual alcoholic poisoning" (1870: 12). Sedentary types, children and the elderly should drink less than this, which is why the Limit fluctuates between 1 and 2 ounces. He warned that many ordinary middle and upper class drinkers - "moderate diners-out" and "virtuous dancing young ladies" - were drinking up to twice as much as his limit allowed (1870: 14). This was partly due to ignorance; anticipating our own problems with the contemporary unit (Boniface et al., 2013), Anstie warned that few people knew very much about what he called the "comparative alcohol 
potency" of different drinks, and this was compounded by variations in glass sizes, which he thought were getting bigger, as well as by the vagueness of patients' descriptions of their consumption (1870: 11). But he also believed that drinkers' own definitions of moderation were too generous:

...we wish to compel the upper and middle classes, and their medical advisers, to look the facts of alcoholic consumption honestly in the face. No one who is at all conversant with the habits of the wine-drinking classes will deny that such a daily allowance of alcohol as we have above mentioned is distinctly within the average consumption of persons of moderate habits as the ways of society go; and indeed we fear that a good many persons will characterize it as utopian in its standard of temperance. (1870: 13)

Anstie's research allowed him to set a daily limit based on experimental physiological research, rather than how drinkers (or their doctors) thought or felt about their drinking. Influential writers on public health and hygiene took up his 'daily allowance' after his early death in 1874.

Anstie’s Limit: from Medicine to Public Debate

Perhaps the most important of Anstie's champions was the hygienist Edmund Alexander Parkes, who incorporated it into later editions of his Manual of Practical Hygiene (1891). Parkes' own research in this field had reached very similar conclusions, and he told Anstie "Your investigations on alcohol seemed to give for the first time a scientific expression to the phrase 'moderation"' (1872: 83). By 1876 Parkes was able to tell the readers of his On Personal Care of Health that "When the amount of alcohol is kept within what may be termed the limit of moderation (viz. 11/2 fluid ounces of pure, i.e. 
what is called absolute alcohol, in twenty-four hours), it is impossible to say, from experiments on strong healthy men, that harm is done" (1876: 63). In the final edition of his important Manual of Practical Hygiene Parkes credited Anstie with the discovery of the 11/2 ounce limit (1876: 340-341). Other medical writers discussed this limit: Benjamin Ward Richardson - a champion of medical temperance but a good friend of Anstie's - discussed Anstie's work on the elimination of alcohol in one of his popular lectures (1883); Thomas R Fraser, Professor of Materia Medica at the University of Edinburgh, also cited Anstie's work on elimination (1880); and Isaac Burney Yeo, Professor and Physician at King's College, London and King's College Hospital set the daily maximum at "one to one and a half fluid ounces", though he did not mention Anstie (1890). However all three writers gave the credit for the one and a half ounce limit to Parkes, even where they cited his Manualwhich itself acknowledged Anstie.

While Anstie was highly thought-of in the United States, when W. S. Greenfield set the safe daily limit at 11/2 ounces he cited Parkes, just as his English colleagues had done (1887). In Canada, Charles Gordon Richardson's aggressive defence of moderation leant heavily on Anstie's arguments while referring to the two-ounce limit (1888). Last, but perhaps most importantly, thirty years after Anstie's death the Committee of Fifty - the influential US research group investigating drinking at the turn of the century - cited his limit to settle "the question as to the amount of alcoholic drinks which can be used freely by the average adult without producing bad results"; "The English standard, as formulated by Anstie, is the equivalent of one and one half (1/1/2) ounces of absolute alcohol per day" (Billings et al., 1905: 32). Given that it has been argued that the Committee established the idea of moderate drinking that came to dominate American policy after the repeal of Prohibition, it seems likely that Anstie had been enormously influential in the US as well as in Britain (Levine, 1983). 
By the 1890s it seems likely that the Limit was well known to medical practitioners; the two cases we outline below suggest that the educated public might also have been aware of it too, though not perhaps of Anstie’s association with it. In 1891 Sir Dyce Duckworth, Physician and lecturer in medicine at Barts, physician to the Prince of Wales, and gout specialist (Garrod, 2004), mentioned the 'utmost limit' of one or one-and-a-half ounces a day in a paper read at the International Congress on Hygiene (Anon., 1891). However his paper at the Fourth International Congress on the Abuse of Alcohol at The Hague received more attention because he told an audience sympathetic to abstinence that
"He knew of no evidence to prove that a moderate consumption of alcoholic liquid taken with other food was injurious to the best health of the textures of the human body, or incapacitated it for its highest functions ... He could give no exact definition of what moderation meant in this matter for most people, but he assumed that the utmost limit or equivalent of alcohol taken in any day should not exceed one ounce or one ounce and a-half' (Anon, 1893a: 8).

\begin{abstract}
The incident was widely reported in newspapers in Britain, New Zealand, Canada, and the US. Critics of temperance took it up, and Duckworth was applauded by the drink trade. However other commentators noted that if his limit was right then there were many more immoderate drinkers than had been imagined (Anon, 1893b); keeping to it would "would speedily mean the reduction to beggary of all the race of opulent brewers" (Anon, 1893c). Reiterating this point at an international congress on life assurance medicine in 1901, Duckworth's views - and his infelicitous phrase 'immoderate moderate drinkers' - were noted by the Journal of the American Medical Association (Anon., 1901) and by a number of US newspapers, all mentioning his definition of a two-ounce 'physiologic limit' (e.g. Anon., 1902).
\end{abstract}


Another doctor's espousal of this limit also generated controversy. Mortimer Granville, a London society doctor specialising in gout and nervous diseases, wrote to the Times claiming that "incalculable harm has been done to the human organism... by the spread of teetotal views and practices"; he subsequently argued that while no one should drink more than two ounces of pure alcohol a day, drinking less than this was dangerous (Granville, 1891a; 1891c). Granville, like Duckworth, beleved the limit allowed drinkers to approach the problem of intemperance rationally:

"Let drinking be put on a rational basis; let the people be taught how much absolute alcohol they ought to consume in 24 hours - never more than two ounces - and let them be told, or take pains to find out for theselves, precisely how much of absolute alcohol, each favourite beverage contains, and arrange their "drinks" accordingly; and drunken England will be drunken no longer...” (1891b).

Granville was farsighted enough to realise that the limit would have to travel beyond medicine into people's everyday lives, echoing (but not acknowledging) Anstie's argument that the drinking public needed to be educated about the relative strengths of different drinks. To help drinkers, Granville suggested the mandatory labelling of bottles and beer pumps with this information :

"A short Act of Parliament, compelling every vendor of wine and beer to state the proportion of absolute alcohol it contains, and rendering it a misdemeanour to sell a bottle not labelled explicitly to this effect, or to supply ale or beer on draught without a printed notice of the same import being affixed to the drawing machine in every bar, would do more to put a stop 
to drunkenness in this country than any teetotal or temperance movement, however well organized" (1891c).

\begin{abstract}
These sallies generated a good deal of discussion within and beyond the pages of the Times, much of it hostile, and Granville was savagely attacked by the British Medical Association, temperance workers, and others. However it seems likely that this controversy communicated the idea of moderate drinking, the limit, and questions of alcoholic strength to a wider public. One valuer of wines and spirits noted ino the Times that "One of your correspondents... asks for a little explanation of the learned doctor's 2oz. dictum, being as a layman apparently 'fogged' on the subject of 'absolute alcohol'." Providing a list of examples of the volume of different drinks containing this amount of alcohol, he concluded "your readers can amuse themselves with a very pretty calculation, and drink, if they please, by equation" (Hudson, 1891).
\end{abstract}

It seems likely that the Limit had become well-established within mainstream medicine by the start of the twentieth century, and that the widespread reporting of these stories would have made the limit well-known to the public. In many ways these discussions prefigure arguments about the contemporary unit, and we will return to this in the conclusion. However we know from the contemporary unit that these kinds of pronouncements can be received in many different ways. The limit could only work if medical practitioners and ordinary drinkers took it seriously. While it is hard to establish whether this was the case, and there was certainly opposition both from teetotallers and those opposed to any controls on drinking, it does seem likely that Anstie's Limit was already working in insurance circles to change medical practice. 
The Limit in Life Assurance

We can find the Limit at work in life assurance in two places: firstly, in the handbooks issued to medical referees to help them establish whether applicants for life assurance were drinking moderately, and secondly in its use as a measure of the American life assurance industry's exposure to drink-related mortality.

All nineteenth-century insurance firms employed doctors to vet applicants. At first they entrusted this work to their chief medical officers, but in the second half of the century they began to employ local doctors to examine applicants. The 14 Scottish Assurance Offices paid for nearly 9000 examinations in 1854, for example, which cost about $\mathcal{f}_{6} 6000$ (Anon., 1855), and Marguerite Dupree suggests that "a substantial proportion of the medical profession gained valuable parttime appointments which helped to alter the diagnostic techniques of the profession more generally" (1997: 102) Because variations in assessment between doctors would threaten the firm's finances, with over-enthusiastic practitioners letting too many bad risks through and overlycautious ones turning away good ones, company medical officers began to publish handbooks for medical examiners in an attempt to standardise practice. Consulting fourteen handbooks (some in multiple editions) published between 1863 and 1929, we found only one that did not ask medical referees to look out for signs of problem drinking. Most accepted that moderation could be safe:

“...the moderate use of stimulants does not tend to shorten life. By "moderate," we mean stimulants taken in small quantities - with the meals - and not more frequently than twice in the day.” (Pollock and Chisholm, 1895: 65) 
This raises the question of quantity. Guidebooks that recommended recording the amount consumed, rather than the drinker's habits, appeared before Anstie defined his Limit (e.g. Brinton, 1863) but this became increasingly common as the century progressed. Many recommended this as a way of getting applicants - notoriously untrustworthy when it came to talking about their drinking - to give more reliable information (Levan, 1885). By the turn of the century examiners were asked to quantify the applicants' consumption in terms of the volume of pure alcohol, as Anstie had suggested.

Anstie's work was cited in one handbook as early as 1870 , though the limit itself was not mentioned (Allen, 1870). It is not until 1908 that we see a direct reference to "the physiological amount of one and a half ounces of absolute alcohol", which is attributed to Parkes rather than Anstie (Brockbank, 1908: 181). Twenty years later this 'physiological amount' seems to have become fairly well-fixed, with the Limit appearing in both editions of James Paterson MacLaren's handbook, written in Cape Town but intended as a manual for the Anglo-Saxon world. MacLaren asked "What is a 'sober and temperate' person in the insurance sense? ... The best authority is that of a physiologist, and there is none higher than that of Parkes" (1927: 157, original emphasis). He then discussed the research of Parkes, "Ainslie" [sic] and Wollowicz, one of Anstie's collaborators. In the US the inebriety expert Thomas Crothers complained that some firms "draw a line in cases of moderate drinking at what is called 'Anstie's' limit of daily allowance”' (1891: 188), so at least some companies were instructing doctor to use it.

\footnotetext{
By the start of the twentieth century medical referees were expected to quantify how much alcohol applicants consumed each day, and in some cases they were explicitly referred to Anstie, Parkes, and the Limit itself. Whether or not medical referees agreed with these arguments about
} 
risk and moderation is in a sense not the point. Companies took a dim view of doctors who exposed them to unnecessary risks, and as examinations became more a question of collecting data for the firm's clerks, doctors' opinions became increasingly unimportant (Porter, 2000; Alborn, 2009). As a result it is quite possible that the popularity of life assurance in nineteenthcentury Britain would have changed medical practice in assessing drinking without having to change medical thinking. Since it is estimated that about 30\% of the British population had life insurance policies of some kind by 1890 (Alborn, 2009: 20), many doctors would have been trained to undertake medical examinations for life insurance, and these techniques, and perhaps ideas, may well have taken root in general practice (Jureidini and White, 2000).

However in the early years of the twentieth century Anstie's limit began to be used as a way of evaluating life assurance practices. In 1908 forty-three of the oldest US companies shared their mortality experience to improve their understanding of particular risks. This Medico-Actuarial Investigation, covering two million lives, was chaired by Arthur Hunter, the actuary at New York Life. Hunter reported that this sample contained very many people who were indulging in the 'Steady, free use of alcohol': moderate drinkers who drank frequently, as opposed to having occasional sprees (binges). This group could be further divided

"according to whether a conservative or a liberal interpretation of the expression "Steady, free use" had been adopted. In the latter section were placed the risks from those companies which used a standard as high or higher than Anstie's limit of two ounces of alcohol per day; and in the former, all the companies which used less than Anstie's limit.” (1914: 190) 
The Limit had become a useful way of categorizing safe and risky classification practices within the industry. Firms with a liberal definition were straying from safe ground. The health writer Eugene Lyman Fisk reviewed these figures and concluded that: “The man who passes Anstie's limit goes into a sub-standard class, and a poor sub-standard class at that. While individually he may escape, he belongs to a class that is fated to lose twice as many men in the same space of time as the general average" (1917: 23-4). The Limit had become a benchmark for individuals, individual firms, and the industry as a whole.

However by 1922 Hunter and Oscar Rodgers, New York Life’s chief Medical Officer, had become concerned that the Limit was set too high: the industry's records demonstrated that hundreds of thousands of moderate drinkers were still dying earlier than expected.

“the evidence is conclusive that the so-called Anstie's limit of one and a half ounces, or three tablespoons of alcohol a day, is far too liberal. There appears to be no limit within which alcohol may be entirely harmless. It is as if there were a direct relation between the amount of alcohol used and the amount of damage done to the body.” (1922: 167)

By the 1920s several developments came together to recast the idea of moderate drinking in the US and Britain, and we turn to these before drawing our final conclusions.

\section{Conclusions}


Anstie's Limit was displaced as a measure of moderation in the 1920s for several reasons. Firstly moderation itself became largely irrelevant in those parts of North America affected by prohibition; in the UK attempts to reshape consumption practices (e.g. 'improved' drinking places, Duncan, 2013; Gutzke, 2005) aimed to reduce the amount consumed without setting daily or weekly limits. Secondly while Pearl's study of Alcohol and Longevity (1926) was influential in suggesting that moderation was healthier than abstinence (what we now know as the ' $\mathrm{J}$-shaped curve') it is significant that his definition of a moderate drinker was someone who "drinks a little but never gets drunk" (73), with no interest in the quantity consumed. It might be argued that this does reflect Anstie's Limit - because drunkenness only begins once the Limit has been breached but elsewhere Pearl was adamant that "the toxicity of alcoholic beverages is not proportionate to the percentage of the alcoholic content, but rather to other substances which they contain" (66), and he does not cite any of Anstie's work. There is a larger question here, too, which we cannot go into, about the authority of different kinds of evidence; Anstie began with physiological experiment while both life assurance companies and Pearl used their respective datasets to assess the health of large populations. Squaring the two approaches continues to be difficult, as it is hard to compare an individual to a curve on a graph. Thirdly, the growing centrality of psychiatric rather than physiological ways of defining problem drinking made moderation meaningless. We have already noted Thomas Crothers' criticism of assurance use of the Limit; the superintendent of an inebriate hospital, Crothers was certain that alcoholism was not necessarily triggered by immoderate drinking (Malleck, 2003). Moderation was less important than susceptibility.

As a result of these mingled factors, moderate drinking seemed less harmful than abstinence, in terms of physiology, and alcoholism became separated, to some extent, from consumption. When moderation did need to be quantified, researchers turned to Pearl and to other statistical or public 
health investigations rather than Anstie's medical work. However Anstie does occasionally surface in contemporary discussions, for example in Klatsky's conclusion that "the threshold for net harm in most population studies is exactly where Anstie ... placed his limit” (2004: 327).

However, we think that it is valuable to draw out the many parallels between Anstie's Limit and the limits measured by the contemporary unit. Firstly Granville’s ‘drinking by equation' would require education as well as publicly available information on the strength of different drinks. Secondly, the Limit seemed low to many observers, compared to actual consumption; this either implied an epidemic of dangerous drinking, with the middle classes as much to blame as their social inferiors, or perhaps discredited the Limit as "utopian in its standard of temperance", as Anstie put it. Thirdly the quantification of risk was seen to vary with age, gender and existing health, and actuaries began to explore the complex question of relating individuals to populations. Fourthly Granville anticipated Pearl in arguing that some alcohol might be better than none at all, with the Limit becoming a recommended daily allowance. All of these issues continue to bedevil discussions of drinking in an era where public health quantifications have set the agenda for definitions of harm. We might add that both Anstie and Duckworth noted that differences in expert opinion confused the public, with the latter asking "If such gulfs exist within our own ranks, what opinion is to be formed by the laity who, in these days, are wise enough to think for themselves on most subjects?” (1877: 660).

While both Anstie's Limit and the limits quantified in units were, strictly speaking, arbitrarily decided, that is in a sense a natural consequence of their nature as metrics, especially metrics which have to deal with both individuals and populations. Contemporary commentators have seen the unit as a neoliberal device, but it makes little sense to try to judge the Limit in this way; born from a 
disagreement in medicine that was if anything an argument conducted between liberals, it would go on to be supported by ultra-conservative figures like Duckworth and Granville.

What is more important is whether these limits work, in which contexts, and why. As Porter reminded us in his book on the authority of statistics, "Grades in school, scores on standardized examinations, and the bottom line on an accounting sheet cannot work effectively unless their validity, or at least reasonableness, is accepted by the people whose accomplishments or worth they purport to measure" (1995: 45). Anstie’s Limit and the modern unit both allow for the quantification of moderation and the communication of that quantity. However both have moved on to take on other roles, translated to other places beyond medical research: doctors advising patients on their drinking; retailers informing drinkers about alcohol content in relation to safe limits; clerks grading risks in life assurance; and public health researchers assessing the health of populations. It is patently obvious that quantification works in some of these places, but not in others. As we hope we have demonstrated, a proper evaluation of either the Limit or the limits associated with the contemporary unit requires us to consider these places and contexts, to ask why and how these metrics work differently. Perhaps it doesn't matter that the unit was 'plucked out of the air'; perhaps it is more important to ask what happened next.

Acknowledgement of funding and conflict of interest.

The authors did not receive any additional funding for this research. There is no conflict of interest. 
References

Alborn, T. (2001). Insurance against Germ Theory: Commerce and Conservatism in Late-Victorian Medicine. Bulletin of the History of Medicine, 75, 406-445.

Alborn, T. (2009). Regulated Lives: Life Assurance and British Society, 1800-1914. Toronto: University of Toronto Press.

Allen, J. A. (1870). Medical examinations for life insurance, sixth edition. New York: J H and C M Goodsell.

Anon. (1855). Statistics. Medical Examinations in Scotland for Life Assurance Companies. Edinburgh Medical Journal, 1, 553-4.

Anon. (1874a, September 19). The Lancet. In Memoriam: Francis Edmund Anstie, p. 427.

Anon. (1874b, September 19). The Lancet. Obituary: Francis Edmund Anstie, p. 433-4.

Anon. (1891, Aug 14). A Novel Punishment For Drunkards. The Manchester Guardian, p. 6.

Anon. (1893a, August 17). An Anti-Alcohol Congress. Extraordinary Debate. Birmingham Daily Post, p. 8 . 
Anon. (1893b, August 18). The International Temperance Congress. The Sheffield \& Rotherham

Independent, p. 2.

Anon. (1893c, August 22). Editorial. The North-Eastern Daily Gazette, p. 2.

Anon. (1901). Moderate Drinking And Total Abstinence. Journal of the American Medical Association, 37 , 1396.

Anon. (1902, February 11). Immoderate Moderate Drinking. American Medicine. The Morning

Oregonian, pp. 6.

Anstie, F. E. (1862). Alcohol. Is it Food, Medicine, or Poison? Combill Magazine, 5, 707-716.

Anstie, F. E. (1865, September 23) On The Physiological And Therapeutical Action Of Alcohol. The Lancet, pp. 343-345.

Anstie, F. E. (1870). On the uses of wines in health and disease. New York: J S Redfield.

Bell, E. M. (1953). Storming the citadel: the rise of the woman doctor. London: Constable.

Berridge, V. (1977). Opium Eating and Life Insurance. British Journal of Addiction, 72, 371-377. 
Billings, J. S., Eliot, C. W., Fortune, H. W., Greene, J. L., and Peabody, F. G. (1905). The Liquor

Problem. A Summary Of Investigations Conducted By The Committee Of Fifty 1893-1903. Boston: Houghton Mifflin Company.

Boniface, S., Kneale, J. and Shelton, N. (2013). Actual and Perceived Units of Alcohol in a Self-

Defined 'Usual Glass' of Alcoholic Drinks in England. Alcoholism: Clinical and Experimental Research, $37,978-83$.

Brinton, W. (1863). On the medical selection of lives for assurance. New York: John Hopper.

Brockbank, E. M. (1908). Life Insurance and General Practice. London: Henry Frowde, Hodder and Stoughton.

Crothers, T. D. (1891). The Relation Of Life Insurance To Inebriety. Journal of the American Medical Association, XVI, 187-190.

Duckworth, D. (1877, November 10). On The Medical Injunction Of Stimulants In Disease and in Health. British Medical Journal, pp. 660-662.

Duncan, R. (2013). Pubs and Patriots: The Drink Crisis in Britain during World War One. Liverpool University Press: Liverpool.

Dupree, M. (1997). Other Than Healing. Social History of Medicine, 10, 79-103. 
Earles, M. P. “Anstie, Francis Edmund (1833-1874)”. Oxford Dictionary of National Biography, Oxford University Press, 2004 [http://www.oxforddnb.com/view/article/583, accessed 12 Aug 2013]

Fisk, E. L. (1917). Alcohol; Its Relation to Human Efficiency and Longevity. New York: Funk \& Wagnalls.

Fraser, T. R. (1880). Alcohol: its function and place. Edinburgh: David Douglas.

Garrod, A. E. 'Duckworth, Sir Dyce, first baronet (1840-1928)', rev. Patrick Wallis, Oxford Dictionary of National Biography, Oxford University Press, 2004

[http://www.oxforddnb.com/view/article/32912, accessed 27 July 2012]

Granville, J. M. (1891a, September 15). Drinking And Drunkenness. The Times, pp. 8.

Granville, J. M. (1891b, September 28). Drinking And Drunkenness. The Times, pp. 7.

Granville, J. M., (1891c, October 17). Drinking And Drunkenness. The Times, p. 12.

Greenaway, J. (2003). Drink and British Politics Since 1830: A study in policy-making. Basingstoke and New York: Palgrave Macmillan.

Greenfield, W. S. (1887). Alcohol: Its Use And Abuse. New York: D. Appleton And Company.

Gutzke, D. W. (2005) Pubs and Progressives: Reinventing the Public House in England, 1896-1960. DeKalb: Northern Illinois University Press. 
Hudson, W. (1891, October 15). Drinking And Drunkenness. The Times, p. 7.

Hunter, A. (1914). The Medico-Actuarial Investigation of the Mortality of American and Canadian Life Assurance Companies. Journal of the Institute of Actuaries, 48, 186-197.

Hunter, A., and Rogers, O. H. (1922). Ratings for the Principal Impairments. Proceedings of Association of Life Insurance Medical Directors of America, Vol. VIII. New York: The Knickerbocker Press, 121-67.

Jayne, M., Valentine, G., and Holloway, S. (2012). What Use Are Units? Critical Geographies of Alcohol Policy. Antipode 44, 828-846.

Jureidini, R. and White, K. (2000). Life Insurance, the Medical Examination and Cultural Values. Journal of Historical Sociology, 13, 190-214.

Klatsky A. L. (2004) Alcohol and Cardiovascular Health. Integrative And Comparative Biology, 44, 324 328.

\author{
Kneale, J. and French, S. (2013) 'The Relations of Inebriety to Insurance': geographies of medicine, \\ insurance and alcohol in Britain, 1840-1911. In J. Herring, C. Regan, D. Weinberg and P. Withington \\ (Eds.), Intoxication: Problematic Pleasures (87-109). London: Palgrave Macmillan.
}

Krasnick, C. L. (1985). 'Because there is pain': Alcoholism, temperance and the Victorian physician. Canadian Bulletin of Medical History / Bulletin canadien; histoire de la médecine, 2, 1-22. 
Latour, B. (1987). Science in Action: How to Follow Scientists and Engineers through Society. Milton Keynes: Open University Press.

Latour, B. (1991). Technology is Society Made Durable. In J. Law (Ed.), A Sociology of Monsters: Essays on Power, Technology and Domination (103-132). London and New York: Routledge.

Latour, B., (1993). We have never been modern. New York and London: Harvester Wheatsheaf.

Levan, J. R. (1885). A treatise on medical examination for life insurance. Philadelphia: William F Fell.

Levine, H. G. (1983). The Committee Of Fifty And The Origins Of Alcohol Control. The Journal of Drug Issues, 95-116.

MacLaren, J. P. (1927). Medical insurance examination: modern methods and rating of lives, for medical practitioners, and insurance officials. London: Baillière, Tindall and Cox.

Malleck, D. J. (2003). Thomas Davison Crothers. In J. S. Blocker, Jr., D. M. Fahey, and I. R. Tyrrell, (Eds.) Alcohol and Temperance in Modern History: An International Encyclopedia (179). California: ABCCLIO, Inc.

McAllister, A. (2014) Demon Drink? Temperance and the Working Class (ebook). 
Parkes, E. A. (1872). Letter from Dr Parkes, re 'The Medical Declaration Respecting Alcohol'. The Practitioner, VIII, 82-85.

Parkes, E. A. (1876). On Personal Care of Health. London: SPCK.

Parkes E. A. (1891). A Manual of Practical Hygiene. 8th edition. London: J. A. Churchill.

Pearl, R. (1926). Alcohol and Longevity. Knopf: New York.

Pollock, J. E. and Chisholm, J. (1895). Medical Handbook of Life Assurance for the Use of Medical and other officers of Companies. $4^{\text {th }}$ edition. London, Paris and Melbourne: Cassell and Company Ltd.

Porter, T. M. (1995). Trust in Numbers: The Pursuit of Objectivity in Science and Public Life. Princeton NJ: Princeton University Press.

Porter, T. M. (2000). Life Insurance, Medical Testing, and the Management of Mortality. In L. Daston (Ed.) Biographies of Scientific Objects (226-246). Chicago: University of Chicago Press.

Richardson, B. W. (1883). Ten Lectures on Alcohol. New York: National Temperance Society and Publication House.

Richardson, C. G. (1888). Alcohol; a defence of its temperate use. The National Liberal Temperance Union: Toronto. 
Thom, B. (1999). Dealing With Drink: Alcohol and social policy from treatment to management. London: Free Association Books.

Valverde, M. (1998). Diseases of the will: alcohol and the dilemmas of freedom. Cambridge: Cambridge University Press.

Woiak, J. (1994). 'A Medical Cromwell to Depose King Alcohol': Medical Scientists, Temperance Reformers, and the Alcohol Problem in Britain. Social History, 54, 337-365.

Yeo, I. B. (1890). Food in Health and Disease. Philadelphia: Lea Brothers. 